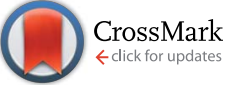

Cite this: J. Anal. At. Spectrom., 2015, 30,635

\title{
Mapping iron gall ink penetration within paper fibres using scanning transmission X-ray microscopy
}

\begin{abstract}
V. Rouchon*a and S. Bernard ${ }^{b}$
Iron gall inks have largely been used for writing in European western countries from the Middle Ages to the twentieth century. Yet, their use may significantly damage the paper through acid hydrolysis and iron catalysed oxidation. These phenomena are not only governed by the chemistry of the ink + cellulose system, but also by the penetration of the ink within the paper sheet. Here, we investigate ink penetration at the scale of a paper fibre using synchrotron-based STXM. This technique allows in situ mapping of the iron redox state and carbon speciation down to the sub-micrometre scale. Linen fibres have been impregnated by iron sulphate, gallic acid and gum Arabic; i.e. the three main ingredients of iron gall inks. Soft X-ray transparent ultrathin foils of impregnated fibres have been extracted using FIB milling. The data reported here evidence that ink components do not penetrate through the paper fibres the same way. In the absence of gum Arabic, gallic acid penetrates within the fibre but mostly remains in the outer part of the cell wall. A significant precipitation of Fe(III) gallate occurs during this migration whereas small amounts of iron (mostly Fe(॥)) penetrate through the inner part of the fibre. The addition of gum Arabic as a binder makes the ink more viscous and significantly jeopardizes its ability to penetrate the fibre. The ink thus remains at the surface of the fibre. Low amounts of iron, essentially Fe(॥), do still penetrate the fibre.
\end{abstract}

Received 23rd October 2014 Accepted 23rd January 2015

DOI: $10.1039 / c 4 j a 00358 f$

www.rsc.org/jaas remain poorly understood. Cellulose hydrolysis, promoted by ink acidity, is often put forward: ${ }^{9}$ ink pH is generally around 2-3 due to the presence of gallic acid and iron solvation complexes which behave as acids. ${ }^{8}$ Nevertheless, the occurrence of hydroxyls or hydrogen peroxides within inked papers having experienced acidic conditions has not yet been evidenced experimentally. Cellulose oxidation, which might be attributable to Fenton reactions, ${ }^{5,10}$ may induce faster reorganization through chain scissions than acidic hydrolysis. ${ }^{8}$ As a matter of fact, cellulose depolymerisation, which can be measured at ambient temperature within a period of a few days, is significantly delayed under oxygen free conditions. ${ }^{8}$ Cellulose oxidation might thus be seen as the driving force of cellulose depolymerisation.

Ink spatial distribution may play an additional role in the preservation/degradation of ancient manuscripts. Examinations of a set of original manuscripts have evidenced the clear correlation between the paper condition and the topography of the ink: ${ }^{11}$ while well preserved paper sheets generally exhibit a thick layer of ink, the most damaged manuscripts do not exhibit any ink layer on their surface but the typical ink elements (iron, sulphur, potassium, calcium) were distributed within the sheets. Little is known regarding the factors that control such distribution, which might either occur during writing or afterwards, depending on ink viscosity, paper permeability and humidity conditions during storage..$^{12,13}$
${ }^{a}$ Centre de Recherche sur la Conservation (CRC, USR 3224), Sorbonne Universités, Muséum national d'Histoire naturelle, Ministère de la Culture et de la Communication, CNRS, CP21, 36 rue Geoffroy Saint Hilaire, 75005 Paris, France. E-mail: rouchon@mnhn.fr

${ }^{b}$ Institut de Minéralogie, de Physique des Matériaux et de Cosmochimie (IMPMC), Sorbonne Universités-MNHN, UPMC Univ Paris 06, CNRS UMR 7590, IRD UMR 206, 61 rue Buffon, 75005 Paris, France 
The composite structure of paper, which consists of a network of cellulosic fibres with several additives, makes it very difficult to model. On the other hand, the ink can be properly described as a suspension of an Fe(III) gallate precipitate in an aqueous solution containing iron sulphate, gallic acid and gum Arabic. $^{2}$ The formation of Fe(III) gallate requires Fe(II) oxidation and therefore depends on oxygen availability. This process may partially occur within the ink pot as well as on the paper sheet or within the paper fibre during ink drying.

Achieving any mechanistic understanding of paper degradation related to ink penetration and drying processes requires experimental research efforts to be made on model fibres under precisely controlled conditions. So far, mapping ink penetration within paper fibres has only been attempted based on Mossbauer spectroscopic measurements ${ }^{2,14}$ or XANES analyses performed at the Fe K-edge. ${ }^{15,16}$ Yet, the spatial resolution of these techniques (about $2 \mathrm{~mm}$ for Mossbauer spectroscopy and about 20-30 $\mu \mathrm{m}$ for Fe K-edge XANES spectroscopy) are not sufficient to properly map submicrometric redox heterogeneities within paper fibres. Here, we report synchrotron-based scanning transmission X-ray microscopy (STXM) data to demonstrate the capabilities of this technique for investigating ink distribution within paper fibres down to the sub-micrometre scale.

\section{Materials and methods}

\section{Investigated materials}

Two different inks have been used for the present study. The first one, hereafter referred to as "Fe $+\mathrm{Ac}+\mathrm{Gu}$ ", contains $9 \mathrm{~g} \mathrm{~L}^{-1}$ of gallic acid monohydrate (Aldrich, 398225), $40 \mathrm{~g} \mathrm{~L}^{-1}$ of $\mathrm{Fe}(\mathrm{II})$ sulphate heptahydrate (Aldrich, 215422) and $80 \mathrm{~g} \mathrm{~L}^{-1}$ of gum Arabic (Aldrich, G9752), while the second one, hereafter referred to as "Fe + Ac", contains similar concentrations of gallic acid monohydrate and $\mathrm{Fe}(\mathrm{II})$ sulphate heptahydrate but no gum Arabic. These inks can be seen as realistic equivalents of the inks used for ancient manuscripts. ${ }^{\mathbf{8 1 7}}$ Solutions have been let in the ink pot for 3 months before use in order to promote $\mathrm{Fe}$ (III) gallate precipitation.

Bleached elemental chlorine free (ECF) linen fibres have been chosen for this study. They are mainly composed of cellulose and hemicellulose. ${ }^{18}$ They are manufactured with flax fibres that originally contain some percentage of wax, lignin, pectin $^{19}$ and fatty acids ${ }^{20}$ which are removed during the ECF bleaching process. Linen fibres present a composite structure oriented along the fibre axis ${ }^{\mathbf{1 8 , 2 1}}$ and composed, from the inner to the outer part, of a lumen, of a secondary cell wall and of a primary cell wall. The lumen is a void corresponding to the cell cytoplasm that was present during the plant growth and disappeared during the fibre bleaching treatment. The secondary cell wall is several micrometres thick and makes most of the fibre. Its main components are oriented highly crystalline cellulose fibrils encrusted in hemicellulose and non-cellulosic polysaccharides (NCPs). ${ }^{19}$ The primary cell wall, about $0.2 \mu \mathrm{m}$ thick is made of similar components but is poorly organised compared to the secondary cell wall.

The fibres have been separated from the wet pulp, individually dried for 24 hours at $23{ }^{\circ} \mathrm{C}$ and $50 \%$ of relative humidity
(RH), immersed for 10 seconds within the prepared inks and dried again for 24 hours.

\section{Focused ion beam (FIB)}

A focused ion beam (FIB) lift-out method has been performed using the FEI STRATA DB 235 FIB system operating at the IEMN (Lille, France). This technique has been used to prepare soft Xray transparent $\sim 15 \mu \mathrm{m} \times 5 \mu \mathrm{m} \times 80 \mathrm{~nm}$ cross-sections across the ink-impregnated linen fibres. A $30 \mathrm{kV} \mathrm{Ga}^{+}$beam operating at $\sim 20 \mathrm{nA}$ has excavated the sample to a depth of $5 \mu \mathrm{m}$ from both sides of a $2 \mu \mathrm{m}$ thick section. This section has then further been thinned to $\sim 80 \mathrm{~nm}$ with a glancing angle beam at lower beam voltage $(5 \mathrm{kV})$ and current $(\sim 100 \mathrm{pA})$, in order to remove the layer of damage left by high-energy ions as advocated by Obst et $a .^{22}$ It is noteworthy that, this procedure maintains textural integrity, even in the case of loosely consolidated materials ${ }^{23,24}$ and prevents shrinkage and deformation of micro-scale to nano-scale pores, even in the case of highly sensitive materials. ${ }^{25,26}$ Milling at relatively low Ga-ion currents at the final stages of sample preparation minimizes common artefacts like local gallium implantation, mixing of components, creation of vacancies or interstitials, creation of amorphous layers, local compositional changes or re-deposition of the sputtered material on the sample surface. ${ }^{27,28}$ In addition milling at low Ga-ion currents prevents significant changes in the speciation of complex carbon-based polymers as evidenced from STXM-based C-XANES data. ${ }^{29}$ After milling, the foils have been exposed for a few days to air (during post shipping), then stored under vacuum until analysis.

\section{Scanning transmission X-ray microscopy}

STXM is a synchrotron-based transmission spectro-microscopy technique using a monochromatized X-ray beam from a synchrotron source. This technique allows both microscopic observations and spectroscopic measurements. For STXM imaging, the X-ray beam is focused on the sample using a zone plate, and a 2-D image is collected by scanning the sample at a fixed photon energy at a spatial resolution of about $20 \mathrm{~nm}$. The image contrast results from differential absorption of X-rays, which depends on the chemical composition of the samples. Xray absorption near edge structure (XANES) spectra can be obtained by collecting image stacks. Image stacks are collected by scanning selected sample areas with energy increments of $0.1 \mathrm{eV}$ over the energy range of interest (275 to $350 \mathrm{eV}$ for the carbon $\mathrm{K}$ absorption edge and 695 to $755 \mathrm{eV}$ for iron $\mathrm{L}$ absorption edge for example). The procedure for collecting an image stack thus consists of measuring the XANES spectrum at a specific element edge on each pixel of an image (one pixel can be as small as $20 \mathrm{~nm} \times 20 \mathrm{~nm}$ ). Counting times are of the order of a few milliseconds or less per pixel. At the C K-edge, absorption peaks constitute sensitive indicators of the local chemical bonding environment surrounding the carbon atoms in question and correspond to transitions from inner shell $1 \mathrm{~s}$ electrons to both unoccupied $\pi^{*}$ (antibonding) and low lying $\sigma^{*}$ orbitals. At the $\mathrm{Fe}_{2,3}$ edges, spectral features correspond to transitions from L shell electrons to final states of core shells 
(i.e., empty d-states) and provide precise information on the Fe redox state.

Measurements of the present study have been done using the STXM located on beamline 10ID-1 (SM beamline ${ }^{30}$ ) at the Canadian Light Source (CLS). Beamline 10ID-1 (CLS) uses soft X-rays (130-2500 eV) generated with an elliptically polarized undulator (EPU) inserted in the $2.9 \mathrm{GeV}$ synchrotron storage ring (250-100 mA). The microscope chamber was evacuated to 100 mTorr after sample insertion and back-filled with He. Energy calibration was accomplished using the well-resolved $3 \mathrm{p}$ Rydberg peak at $294.96 \mathrm{eV}$ of gaseous $\mathrm{CO}_{2}$ for the C K-edge. Alignment of images of stacks and extraction of XANES spectra were done using the aXis2000 software (ver2.1n). Normalization to carbon or iron quantities and determination of spectral peak positions, intensities and widths have been done using the Athena software package. ${ }^{31}$ The C-XANES spectra shown in the present contribution correspond to homogeneous organic-rich areas of several hundreds of nanometres. Although radiation damage per unit of analytical information has been shown to be typically 100-1000 times lower in STXM-based XANES spectroscopy than in TEM-based EELS, ${ }^{32,33}$ the C-XANES data shown here have been collected following the procedures for X-ray microscopy studies of radiation sensitive samples recommended by Wang et al. ${ }^{34}$ Given that the C-XANES spectra presented here have been normalized to the total carbon amount (corresponding to the intensity the absorption step between 270-280 eV, i.e. below the edge, and $310-330 \mathrm{eV}$, i.e. above the edge) and assuming that the oscillator strength of a given functional group is essentially the same in organic compounds of similar chemistry, the relative concentrations of the different functional groups can be discussed qualitatively.

\section{Results}

\section{Visual observations}

A drop of "Fe + Ac" solution has been deposited on a filter paper preliminarily impregnated with bathophenanthroline (Fig. 1a). The black central part of the stain corresponds to the Fe(III) gallate precipitate already formed in the ink pot whereas the grey surrounding area is attributed to the Fe(III) gallate precipitate forming during the drying process. The larger pink halo is (a)

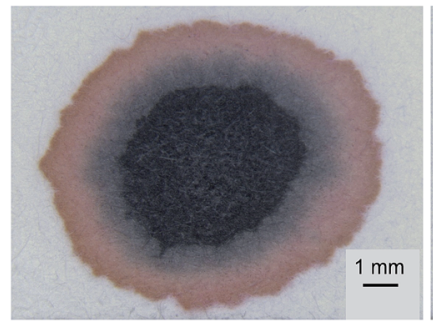

(b)

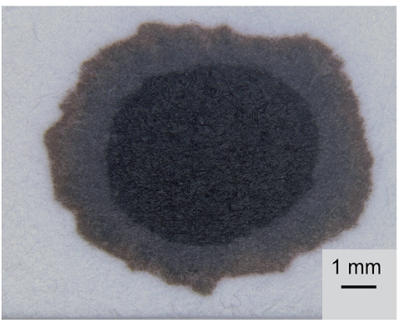

Fig. 1 Photographs showing patterns of ink stains on the filter paper preliminarily impregnated with bathophenanthroline. (a) "Fe + $\mathrm{Ac}$ " sample and (b) "Fe + Ac + Gu" sample. The pink halo corresponds to the $1: 3 \mathrm{Fe}(॥)$-bathophenanthroline chelate thus revealing the presence of Fe(II) compounds. due to the formation of the $1: 3 \mathrm{Fe}(\mathrm{II})$ bathophenanthroline chelate (Fig. 1a). It attests to the persistence in the ink of Fe(II) species resulting from the low availability of oxygen within the ink pot as well as from the high capability of gallic acid to reduce $\mathrm{Fe}(\mathrm{III}){ }^{35}$ The incorporation of a high amount of gum Arabic in the solution makes it significantly more viscous. A drop of "Fe + $\mathrm{Ac}+\mathrm{Gu}$ " solution deposited on a bathophenanthroline impregnated paper therefore behaves differently (Fig. 1b). The stain shows a black halo characteristic of the $\mathrm{Fe}(\mathrm{III})$ gallate precipitate with a pinkish hue that attests to the presence of $\mathrm{Fe}(\mathrm{II})$. The migration of these components seems to be restricted by the presence of gum that acts as a binder.

Fibres impregnated with "Fe + Ac" and "Fe + Ac + Gu" solutions present different aspects under the stereomicroscope. The "Fe + Ac" fibre shows an even black aspect and its surface patterns remain visible (Fig. 2a), suggesting that the ink has largely penetrated into the fibre. In contrast, an uneven deposition of the ink is observed on "Fe $+\mathrm{Ac}+\mathrm{Gu}$ " fibres: some parts of the fibres seem to be untouched by the ink whereas some others are embedded in a thick ink layer (Fig. 2b).

\section{Blank linen fibre}

The FIB foil extracted from the reference ink-free linen fibre displays two layers centred on the lumen void, consistent with the known structure of linen fibres. These layers show similar, although slightly different, C K-edge XANES spectra that are comparable to that of a cellulose model sample (Sigmacell Cellulose, Sigma-Aldrich) (Fig. 3). ${ }^{29}$ Three main peaks are present at $288.6 \mathrm{eV}, 286.7 \mathrm{eV}$ and $285.1 \mathrm{eV}$. The C K-edge XANES of the outer layer of the linen fibre exhibits an additional spectral feature at $289.5 \mathrm{eV}$.

\section{"Fe + Ac" fibre}

The primary cell wall of the fibre is not visible on the scanned area, which was focussed on the secondary cell wall. The C K-

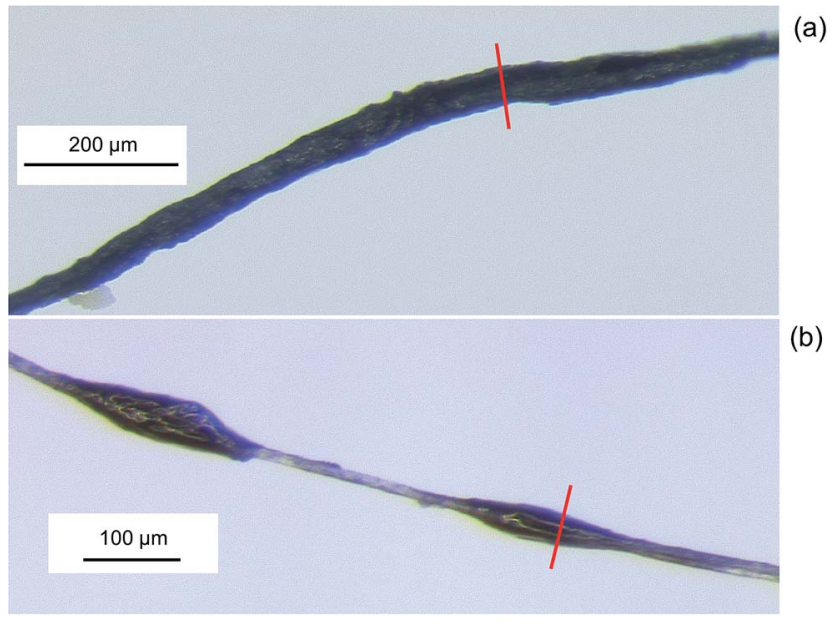

(a)

(b)

Fig. 2 Photomicrographs showing the inked fibres before FIB foil extraction (red lines correspond to the location from which FIB foils have been extracted). (a) "Fe + Ac" sample and (b) "Fe + Ac + Gu" sample. 
(a)

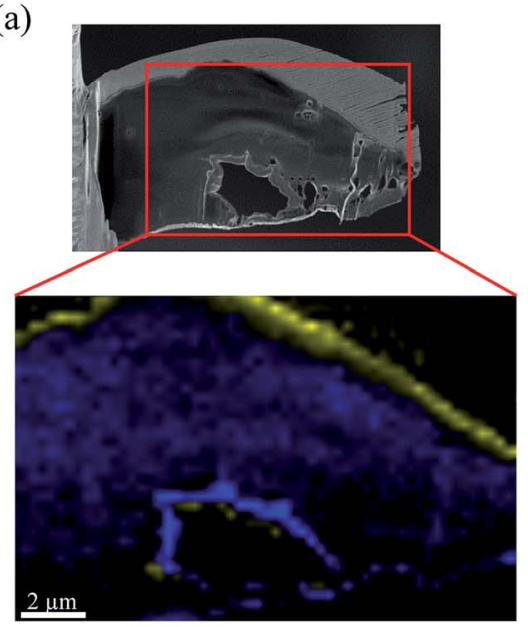

(b)

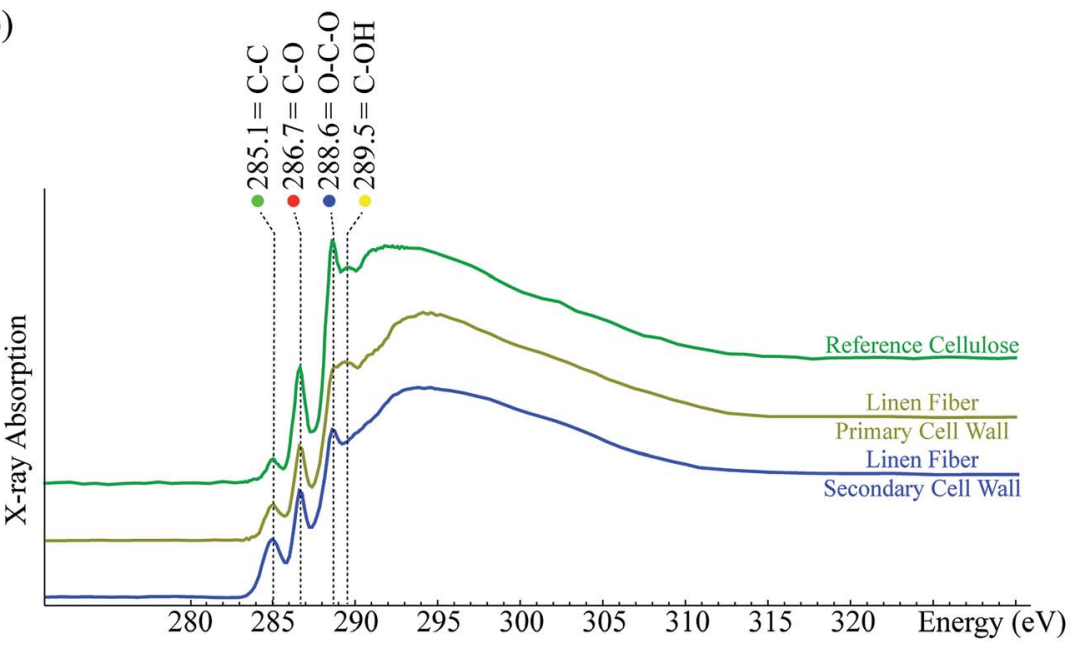

(c)

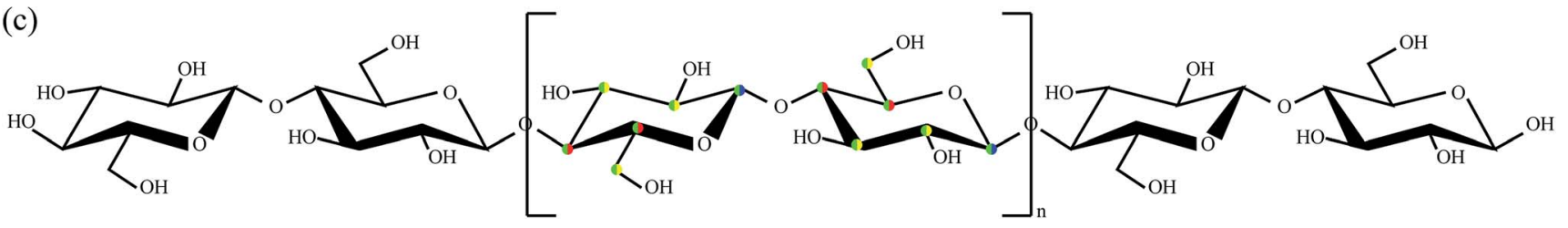

Fig. 3 STXM characterization of a FIB foil extracted from a reference linen fiber. (a) FIB-SEM image of the investigated FIB foil (top) and the compositional map showing the spatial distribution of the carbon compounds whose XANES spectra are shown in (b). (b) C K-edge XANES spectra of the carbon compounds constituting the linen fiber primary and secondary cell walls. A reference spectrum of cellulose is also shown for comparison. (c) Schematic chemical structure of cellulose.
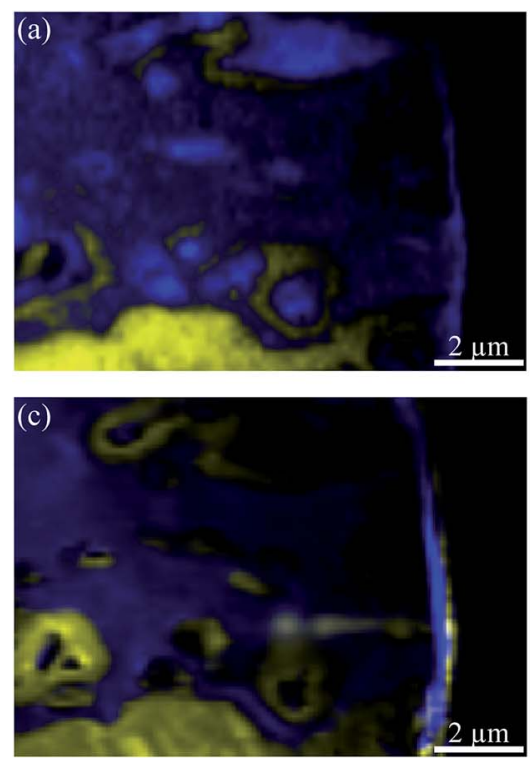
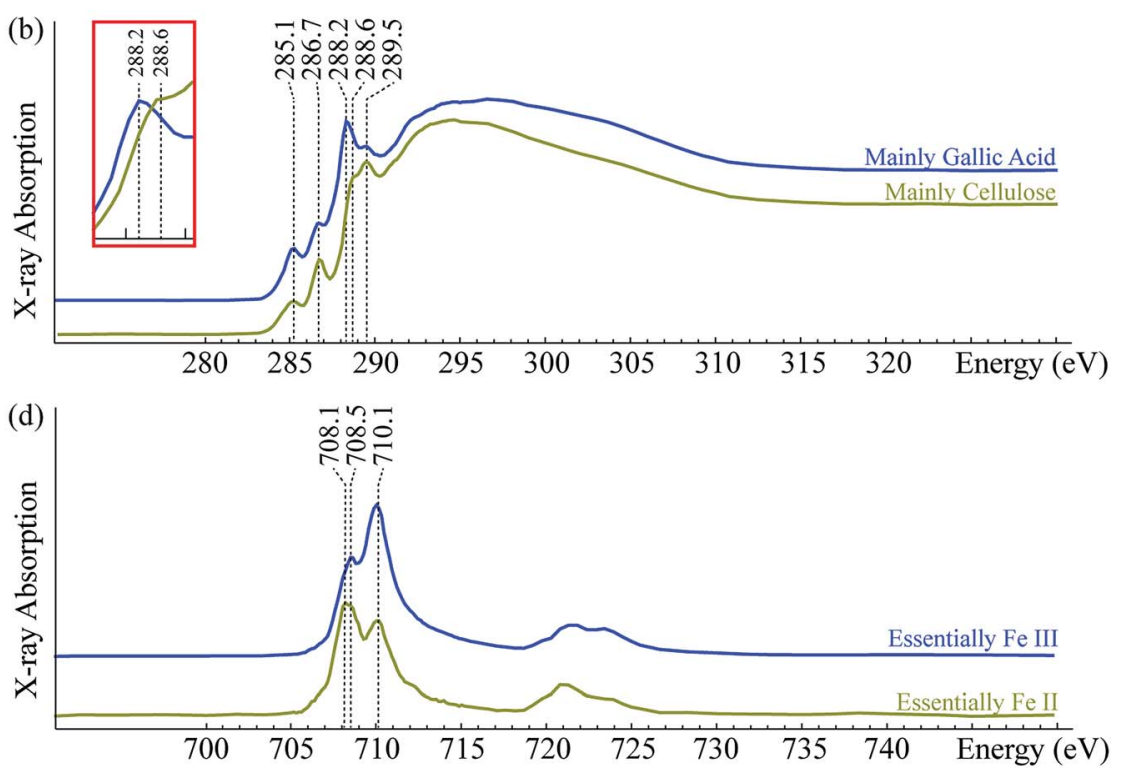

Fig. 4 STXM characterization of the FIB foil extracted from the Fe + Ac sample. (a) Compositional map showing the spatial distribution of the carbon compounds whose XANES spectra are shown in (b). (b) C K-edge XANES spectra of the carbon compounds found within the FIB foil. (c) Compositional map showing the spatial distribution of the iron phases whose XANES spectra are shown in (d). Fe L-edge XANES spectra ( $\mathrm{L}_{2,3}$ edge) of the iron phases found within the FIB foil. See the text for details.

edge XANES of the inner part of this cell wall (Fig. 4) appears similar to the one of cellulose from the blank fibre (Fig. 3), with spectral features at 285.1, 286.7, 288.6 and $289.5 \mathrm{eV}$. The C Kedge XANES of the outer part of the secondary cell wall (Fig. 4) exhibits an additional feature at $288.2 \mathrm{eV}$ that is also present on the C K-edge XANES of gallic acid. ${ }^{36,37}$ It is of note that the spatial distribution of the iron redox state correlates with the distribution of these two organic signatures: gallic acid rich 

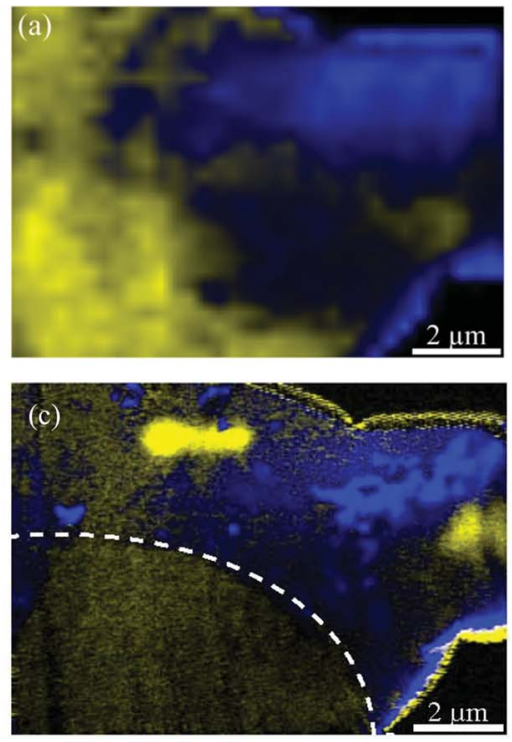
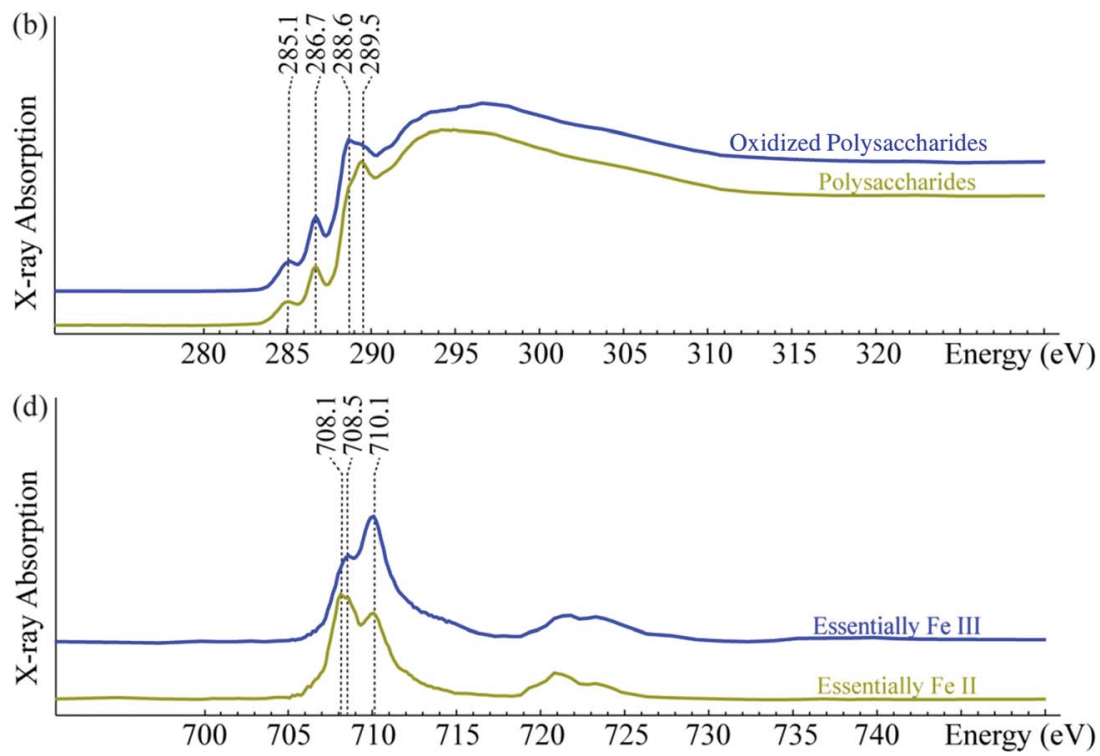

Fig. 5 STXM characterization of the FIB foil extracted from the Fe + Ac + Gu sample. (a) Compositional map showing the spatial distribution of the carbon compounds whose XANES spectra are shown in (b). (b) C K-edge XANES spectra of the carbon compounds found within the FIB foil. (c) Compositional map showing the spatial distribution of the iron phases whose XANES spectra are shown in (d). (d) Fe L-edge XANES spectra $\left(\mathrm{L}_{2,3}\right.$ edge) of the iron phases found within the FIB foil. See the text for details.

areas are also rich in iron and display essentially Fe(III) phases, while cellulose rich areas are much poorer in iron $(\sim 3$ to 4 times less) and display essentially Fe(II) phases.

\section{"Fe + Ac + Gu" fibre}

$\mathrm{The}$ "Fe $+\mathrm{Ac}+\mathrm{Gu}$ " FIB foil has been extracted from a region of the fibre covered by a thick layer of ink (Fig. 2b). This FIB foil shows two main domains (delimited by a dotted line on Fig. 5). The upper region appears to only contain the ink whereas the lower region corresponds to the fibre itself. The $\mathrm{C}$ K-edge XANES of these two areas are relatively similar, consistent with the fact that gum Arabic and cellulose are two polysaccharides containing similar functional groups. However, the intensities of the peaks at $288.6 \mathrm{eV}$ and $289.5 \mathrm{eV}$ differ, thus allowing identifying the ink and the linen fibre. The map of the iron redox state confirms this distribution: the upper region appears to be rich in iron in the form of $\mathrm{Fe}$ (III) phases, consistent with a high concentration of Fe(III) gallate within the ink, whereas the fibre itself, i.e. the lower part of the FIB foil, only exhibits a low concentration of iron $(\sim 3$ to 4 times less), mainly in the form of $\mathrm{Fe}(\mathrm{II})$.

\section{Discussion}

\section{K-edge XANES interpretation}

The two layers observed on the FIB foil extracted from the reference ink-free linen fiber exhibit C K-edge XANES spectra similar to those of a cellulose model (Fig. 3). The latter shows a peak centered at $289.5 \mathrm{eV}$, usually attributed to $1 \mathrm{~s}-3 \mathrm{p} / \sigma^{*}$ transitions of carbons in alcohol functional groups $(\mathrm{C}-\mathrm{OH}),{ }^{29,36,37}$ a main peak at $288.6 \mathrm{eV}$, attributed to $1 \mathrm{~s} \rightarrow \pi^{*}$ electronic transitions of carbons in acetal functional groups $(\mathrm{O}-\mathrm{C}-\mathrm{O}),{ }^{38} \mathrm{a}$ peak at $286.7 \mathrm{eV}$, attributed to $1 \mathrm{~s} \rightarrow \pi^{*}$ electronic transitions of carbons in ether functional groups $(\mathrm{C}-\mathrm{O})^{38}$ and a peak at 285.1 $\mathrm{eV}$, attributed to $1 \mathrm{~s} \rightarrow \pi^{*}$ electronic transitions of carbons linked to another carbon $(\mathrm{C}-\mathrm{C}) .^{38}$

The weak peak at 285.1 eV observed in the C-XANES spectra of the blank linen fibre likely results from irradiation damage related to the FIB milling process as previously reported. ${ }^{38}$ This peak appears to be more important in the secondary cell wall than in the primary cell wall, while it is the opposite for the peak at $289.5 \mathrm{eV}$ characteristic of alcohols. This suggests that the primary cell wall is less sensitive to beam damage than the secondary cell wall, consistent with previous studies that have shown that ion fluxes induce drastic morphological changes in the secondary cell wall of flax fibres while no physical distortion has been reported for the primary cell wall. ${ }^{21}$

The C K-edge XANES spectrum of the ink layer of the "Fe + Ac $+\mathrm{Gu}$ " sample exhibits a less intense peak at $289.5 \mathrm{eV}\left(1 \mathrm{~s} \rightarrow \pi^{*}\right.$ electronic transitions of alcohol functional groups) than the one of the fibre. This may be related to the composition of gum Arabic, which is rich in arabinose, rhamnose and xylose, three sugars that contain less alcohol functional groups than cellulose.

Finally, mapping the distribution of gallic acid relies, for the "Fe + Ac" sample, on the occurrence of a peak at 288.2 eV assigned to the $1 \mathrm{~s} \rightarrow \pi^{*}$ electronic transitions of $\mathrm{C}=\mathrm{O}$ involved in carboxylic functional groups. In contrast, gallic acid has not been detected within the "Fe + Ac + Gu" sample, likely because of its too low concentration within the polysaccharide matrix of gum Arabic and/or cellulose. Alternatively, gallic acid may have undergone chemical reactions during its precipitation with $\mathrm{Fe}(\mathrm{III})$. 


\section{Ink penetration}

The "Fe + Ac" ink can be seen as a suspension of solid Fe(III) gallate particles in a solution of gallic acid and iron sulphate. The dark colour of the ink is enhanced during the drying process due to the formation of $\mathrm{Fe}(\mathrm{III})$ gallate. The maps that are shown in Fig. 4 evidence the penetration of this ink through the linen fibre. Yet, iron appears to be heterogeneously distributed. The outer part of the secondary cell wall exhibits Fe(III) rich areas (likely $\mathrm{Fe}(\mathrm{III})$ gallate precipitates) surrounding Fe-poor patches predominantly composed of $\mathrm{Fe}(\mathrm{II})$. In contrast, iron is present at low concentration but appears to be uniformly distributed within the inner part of the secondary cell wall. Such distribution might be imputed to the presence of gallic acid. As a matter of fact, gallic acid is a large molecule in comparison to iron solutes and likely migrates less easily than soluble iron into the paper fibre. This limited transport directly controls the distribution of $\mathrm{Fe}(\mathrm{III})$ gallate precipitates, which thus only occurs within the outer part of the secondary cell wall. Unlike $\mathrm{Fe}(\mathrm{III}), \mathrm{Fe}(\mathrm{II})$ is present in the form of soluble phases and migrates in the inner part of the fibre. A similar behaviour is evidenced at a larger scale by the chromatographic patterns appearing around a stain of the drying ink (Fig. 1). Most of the dark Fe(III) gallate precipitates that have formed within the ink drop remain in the middle of the stain while two halos appear during drying: a first one composed of newly formed $\mathrm{Fe}(\mathrm{III})$ gallate precipitates and a larger halo mainly composed of $\mathrm{Fe}$ (II) solutes. In contrast, by increasing ink viscosity, the addition of gum Arabic substantially modifies the ability of the ink to penetrate the fibre (Fig. 5). The Fe(III)-rich "Fe $+\mathrm{Ac}+\mathrm{Gu}$ " ink indeed mostly remains outside the fibre while only a small amount soluble Fe(II) migrates within the fibre itself. As evidenced by C-XANES spectroscopy, neither the gum Arabic nor the gallic acid penetrates the fibre.

Altogether, the present study evidences that the different components of the iron gall ink do not behave the same way during ink penetration within paper fibres. In the absence of gum Arabic, ink migrates into the fibre and $\mathrm{Fe}(\mathrm{III})$ gallate precipitates during this migration. Yet gallic acid and $\mathrm{Fe}(\mathrm{III})$ gallate precipitates penetrate less through the fibres compared to soluble $\mathrm{Fe}(\mathrm{II})$. The addition of gum Arabic significantly increases the viscosity of the ink thus preventing the penetration of most of its components. Importantly, with or without gum Arabic, low amounts of soluble Fe(II) appear to fully impregnate the linen fibres.

\section{Concluding remarks}

The present study illustrates the capabilities of STXM to provide unique data for the study of ink penetration through paper fibres. It shows that iron speciation is correlated with the distribution of organic components and that the addition of gum Arabic limits the penetration of the ink into the fibre, yet without preventing Fe(II) solutes from migrating deep into the fibre. As the alteration is generally imputed to Fe(II), STXM appears to be a well-suited tool to characterize the alteration process occurring at the sub-micrometre scale. Additional experiments on ancient manuscripts as well as on model fibres prepared according to ancient paper making processes, considering paper additives such as gelatine (sizing agent) or calcium carbonate (charge), will undoubtedly provide new insights towards a more mechanistic understanding of paper degradation related to ink penetration and drying processes.

\section{Acknowledgements}

We gratefully acknowledge support from the ERC (project PaleoNanoLife-PI: F. Robert). Special thanks go to David Troadec for the preparation of FIB sections. STXM-based XANES data were acquired at beamline 10ID-1 at the CLS, which is supported by the NSERC, the CIHR, the NRC, and the University of Saskatchewan. Special thanks go to Chithra Karunakaran and Jian Wang for their expert support of the STXM at the CLS.

\section{Notes and references}

1 A. Stijnman, in Iron Gall Inks: On Manufacture, Characterisation, Degradation and Stabilisation, ed. J. Kolar and M. Strlic, National and University Library, Ljubljana, 2006, ch. 4, pp. 25-68.

2 C. Burgaud, V. Rouchon, P. Refait and A. Wattiaux, Appl. Phys. A: Mater. Sci. Process., 2008, 92, 257-262, DOI: 10.1007/s00339-008-4503-5.

3 T. Steemers, in Iron Gall Inks: On Manufacture, Characterisation, Degradation and Stabilisation, ed. J. Kolar and M. Strlic, National and University Library, Ljubljana, 2006, ch. 3, pp. 20-24.

4 Tintenfrassschäden und ihre Behandlung, ed. G. Banik and H. Weber, Kohlhammer, Stuttgart, 1999.

5 J. Kolar and M. Strlic, in Iron Gall Inks: On Manufacture, Characterisation, Degradation and Stabilisation, ed. J. Kolar and M. Strilic, National and University Library, Ljubljana, 2006, ch. 11, pp. 181-194.

6 V. S. Selih, M. Strlic, J. Kolar and B. Pihlar, Polym. Degrad. Stab., 2007, 92, 1476-1481, DOI: 10.1016/ j.polymdegradstab.2007.05.006.

7 M. Strlic, E. Menart, I. K. Cigic, J. Kolar, G. de Bruin and M. Cassar, Polym. Degrad. Stab., 2010, 95, 66-71, DOI: 10.1016/j.polymdegradstab.2009.10.011.

8 V. Rouchon, M. Duranton, C. Burgaud, E. Pellizzi, B. Lavedrine, K. Janssens, W. de Nolf, G. Nuyts, F. Vanmeert and K. Hellemans, Anal. Chem., 2011, 83, 2589-2597, DOI: 10.1021/ac1029242.

9 J. Kolar, A. Stolfa, M. Strilic, M. Pompe, B. Pihlar, M. Budnar, J. Simcic and B. Reissland, Anal. Chim. Acta, 2006, 555, 167174, DOI: 10.1016/j.aca.2005.08.073.

10 M. Strilic, J. Kolar, D. Kocar and J. Rychly, in Ageing and Stabilisation of Paper, ed. M. Strilic and J. Kolar, National and University Library, Ljubljana, 2005, ch. 7, pp. 111-132.

11 C. Remazeilles, V. Rouchon Quillet, J. Bernard, T. Calligaro, J. C. Dran, J. Salomon and M. Eveno, Restaurator, 2005, 26, 118-133.

12 V. Rouchon, B. Durocher, E. Pellizzi and J. Stordiau-Pallot, Stud. Conserv., 2009, 54, 236-254. 
13 V. Rouchon, M. Duranton, O. Belhadj, M. Bastier Desroches, V. Duplat, C. Walbert and B. Vinther Hansen, Polym. Degrad. Stab., 2013, 98, 1339-1347.

14 B. Wagner, E. Bulska, B. Stahl, M. Heck and H. M. Ortner, Anal. Chim. Acta, 2004, 527, 195-201, DOI: 10.1016/ j.aca.2004.04.011.

15 M. Wilke, O. Hahn, A. B. Woodland and K. Rickers, J. Anal. At. Spectrom., 2009, 24, 1364-1372, DOI: 10.1039/b904438h.

16 K. Proost, K. Janssens, B. Wagner, E. Bulska and M. Schreiner, Nucl. Instrum. Methods Phys. Res., Sect. B, 2004, 213, 723-728, DOI: 10.1016/s0168-583x(03)01693-8.

17 de Champour and F. Malepeyre, Nouveau manuel complet de la fabrication des encres, Encyclopédie Roret, Paris, 1895.

18 C. Baley, Composites, Part A, 2002, 33, 939-948.

19 C. Morvan, C. Andeme-Onzighi, R. Girault, D. S. Himmelsbach, A. Driouich and D. E. Akin, Plant Physiol. Biochem., 2003, 41, 935-944, DOI: 10.1016/ j.plaphy.2003.07.001.

20 G. Marques, J. C. del Rio and A. Gutierrez, Bioresour. Technol., 2010, 101, 260-267, DOI: 10.1016/ j.biortech.2009.08.036.

21 B. Domenges and K. Charlet, Microsc. Microanal., 2010, 16, 175-182, DOI: 10.1017/s1431927609991292.

22 M. Obst, P. Gasser, D. Mavrocordatos and M. Dittrich, Am. Mineral., 2005, 90(8-9), 1270-1277.

23 R. M. Langford, Microsc. Res. Tech., 2006, 69(7), 538-549.

24 D. Drobne, M. Milani, V. Leser and F. Tatti, Microsc. Res. Tech., 2007, 70(10), 895-903.

25 A. J. Smith, P. R. Munroe, T. Tran and M. S. Wainwright, J. Mater. Sci., 2001, 36(14), 3519-3524.

26 L. E. Thompson, P. M. Rice, E. Delenia, V. Y. Lee, P. J. Brock, T. P. Magbitang, G. Dubois, W. Volksen, R. D. Miller and H. C. Kim, Microsc. Microanal., 2006, 12, 156-159.
27 S. Rubanov and P. R. Munroe, J. Microsc., 2004, 214(3), 213221.

28 J. Mayer, L. A. Giannuzzi, T. Kamino and J. Michael, MRS Bull., 2007, 32(5), 400-407.

29 S. Bernard, K. Benzerara, O. Beyssac, G. E. Brown, L. G. Stamm and P. Duringer, Rev. Palaeobot. Palynology, 2009, 156, 248-261, DOI: 10.1016/j.revpalbo.2008.09.002.

30 K. V. Kaznatcheev, C. Karunakaran, U. D. Lanke, S. G. Urquhart, M. Obst and A. P. Hitchcock, Nucl. Instrum. Methods Phys. Res., Sect. A, 2007, 582, 96-99.

31 B. Ravel and M. Newville, J. Synchrotron Radiat., 2005, 12(4), 537-541.

32 A. Braun, F. E. Huggins, N. Shah, Y. Chen, S. Wirick, S. B. Mun, C. Jacobsen and G. P. Huffman, Carbon, 2005, 43(1), 117-124.

33 A. P. Hitchcock, J. J. Dynes, G. Johansson, J. Wang and G. Botton, Micron, 2008, 39(3), 311-319.

34 J. Wang, C. Morin, L. Li, A. P. Hitchcock, A. Scholl and A. Doran, J. Electron Spectrosc. Relat. Phenom., 2009, 170(13), 25-36.

35 C. Burgaud, V. Rouchon, A. Wattiaux, J. Bleton, R. Sabot and P. Refait, J. Electroanal. Chem., 2010, 650, 16-23, DOI: 10.1016/j.jelechem.2010.09.015.

36 D. Solomon, J. Lehmann, J. Kinyangi, B. Q. Liang, K. Heymann, L. Dathe, K. Hanley, S. Wirick and C. Jacobsen, Soil Sci. Soc. Am. J., 2009, 73, 1817-1830, DOI: 10.2136/sssaj2008.0228.

37 D. Solomon, J. Lehmann, J. Wang, J. Kinyangi, K. Heymann, Y. S. Lu, S. Wirick and C. Jacobsen, Sci. Total Environ., 2012, 438, 372-388, DOI: 10.1016/j.scitotenv.2012.08.071.

38 L. S. Johansson and J. M. Campbell, Surf. Interface Anal., 2004, 36, 1018-1022, DOI: 10.1002/sia.1827. 